\title{
Urosepsis After Percutaneous Nephrolithotomy (PCNL) - a New Prediction Rule and Scoring System
}

\section{Heng Yang}

First Affiliated Hospital of Shihezi University School of Medicine

\section{Zhang Qin Wang}

First Affiliated Hospital of Shihezi University School of Medicine

Zhi Li Liu

First Affiliated Hospital of Shihezi University School of Medicine

\section{Qiang Zhi Hao}

First Affiliated Hospital of Shihezi University School of Medicine

\section{Shen Jing Wang}

First Affiliated Hospital of Shihezi University School of Medicine

\section{Yuan Wang}

First Affiliated Hospital of Shihezi University School of Medicine

\section{Le Yong Li}

First Affiliated Hospital of Shihezi University School of Medicine

\section{Hui Ming Tan}

First Affiliated Hospital of Shihezi University School of Medicine

Biao Qian ( $\nabla$ qb19780312@sina.com )

First Affiliated Hospital of Shihezi University School of Medicine

\section{Research}

Keywords: percutaneous nephrolithotomy, urosepsis, risk assessment scoring system

Posted Date: October 18th, 2021

DOI: https://doi.org/10.21203/rs.3.rs-963655/v1

License: (c) (i) This work is licensed under a Creative Commons Attribution 4.0 International License. Read Full License 


\section{Abstract}

\section{Objective:}

Development and validation of a scoring system to predict the risk of urosepsis after percutaneous nephrolithotomy.

\section{Methods:}

The risk factors associated with urosepsis following PCNL(Percutaneous Nephrolithotomy) were identified by metaanalysis. Based on the degree of association, different scores were assigned to these risk factors. Finally Risk assessment scoring system for urosepsis after percutaneous nephrolithotomy (PCNL) was established and validated using ROC (Receiver Operating Characteristic) curve.

\section{Results:}

Based on the degree of association, Women, age ( $\geq 60 \mathrm{yrs}$ ), diabetes mellitus, blood routine (White blood cells $\geq 10 \times 10^{9} / \mathrm{L}$ ), Urinalysis (White blood cells $\geq+$ ), Urine culture (Positive), stone size $(\geq 2 \mathrm{~cm})$, staghorn stone, hydronephrosis (moderate-severe) were assigned 3, 2, 3, 2, 2, 2, 2, 3, 2 points respectively with a total score of 21 points. The area under the ROC(Receiver Operating Characteristic) curve was 0.913 , at the cut-off point of 8.5 , the sensitivity and specificity were $90 \%$ and $89.4 \%$ respectively.

\section{Conclusions:}

The PuRass scoring system could be a useful tool in predicting the risk of urosepsis after PCNL(Percutaneous Nephrolithotomy). Clinician should pay attention to patients with a score above 8.5 during the perioperative period.

\section{Introduction}

Kidney stone was common urological condition affecting about $12 \%$ of the world population. Percutaneous nephrolithotomy (PCNL) was the treatment of choice for larger kidney and ureteric stones. Urosepsis was rare but devastating complication associated with this procedure and was very difficult to predict ${ }^{[1]}$. Understanding risk factors associated with of post-operative urosepsis was necessary to identify high-risk patients and better counsel patients preoperatively. Clinicians and investigators had focused on pathogenesis, diagnosis and treatment of urosepsis following PCNL(Percutaneous Nephrolithotomy),but few attempts had been made in assessment and reorganization of the preoperative risk factors ${ }^{[2]}$. Thus, we developed a risk assessment scoring system (PuRass) to predict the risk of urosepsis following PCNL (Percutaneous nephrolithotomy).

\section{Materials And Methods}

This study was conducted between January 2013 and December 2016 In Shihezi Medical college. In this study, we retrospectively included 293 patients with kidney stone who had undergone PCNL (Percutaneous nephrolithotomy).

Inclusion criteria: The diagnosis was made with either ultrasonography(USG) or computed tomography (CT), indication of surgery was based on 2014 Chinese diagnosis and treatment of urological disease guidelines.

Exclusion criteria: Cases of sepsis secondary to non-urological infection, urosepsis following percutaneous nephrostomy(PCNL).

\section{Method}


The population was divided into two groups urosepsis and the non-urological cause of sepsis. Risk factors associated with the development of urosepsis were identified using meta-analysis. Also, scores were assigned to risk these factors according to the degree of association. Finally, a risk assessment scoring system was established and validated using ROC(Receiver Operating Characteristic) curve.

The following criteria were assigned ${ }^{[3]}$

$0.9 \leq \mathrm{OR} \leq 1.0$ or $1.0 \leq \mathrm{OR} \leq 1.1$ no association; $0.7 \leq \mathrm{OR} \leq 0.8$ or $1.2 \leq \mathrm{OR} \leq 1.4$ weak association; $0.4 \leq \mathrm{OR} \leq 0.6$ or $1.5 \leq \mathrm{OR} \leq 2.9$ moderate association; $0.1 \leq \mathrm{OR} \leq 0.3$ or $3.0 \leq \mathrm{OR} \leq 9.0$ strong association; $\mathrm{OR}<0.1$ or $\geq 10.0$ very strong association.

Degree of association: no association: 0 , weak association: 1 , moderate association: 2 , strong association: 3 , very strong association: 4

Preoperative data collection included Patient's demographics (sex, age), past medical history (Diabetes Mellitus,DM), Complete blood count, blood urea nitrogen, creatinine, liver function test, urinalysis, and urine culture were done. Imaging methods: Ultrasonography(USG) or computed tomography (CT) were used to determine stone size and location. Patients were evaluated using the newly established scoring system and receiver operating characteristic (ROC) curve and area under the ROC(Receiver Operating Characteristic )curve was used to determine the predictive ability of scoring system.

\section{Statistical analysis}

The database was established using Epidata 3.1, Statistical analysis was performed by using SPSS (SPSS Inc., Chicago, IL, USA, Version 17.0). Probability values $<0.05$ were considered significant. Continuous variables were presented as mean value and standard deviation for descriptive Statistics. Receiver operating characteristic (ROC) curve and area under the ROC ( Receiver Operating Characteristic ) curve was used to determine the predictive ability.

\section{Results}

\section{Establishment of PuRass (Risk Assessment Scoring System)}

The PuRass( Risk Assessment Scoring System)scale was established based on results of meta-analysis (Table.1.a) including the following nine risk factor: female, age ( $\geq 60)$, diabetes mellitus(DM), Full blood count (WBC $\left.\geq 10 \times 10^{9} / \mathrm{L}\right)$, urinalysis(positive), Urine culture(positive), stone size $(\geq 2 \mathrm{~cm})$, stag horn calculi, Hydronephrosis(moderate,severe) and they were assigned 3,2,3,2,2,2,2,3,2 respectively, with a total score of 21 . (Table 1. b)

Table 1 a. Meta-analysis results of risk factors associated with urinary sepsis after PCNL 


\begin{tabular}{|c|c|c|c|c|c|c|c|c|c|}
\hline \multirow[t]{2}{*}{$\begin{array}{l}\text { Research } \\
\text { factors }\end{array}$} & \multirow[t]{2}{*}{$\begin{array}{l}\text { Number of } \\
\text { documents }\end{array}$} & \multirow{2}{*}{$\begin{array}{l}\text { Number } \\
\text { of } \\
\text { cases }\end{array}$} & \multirow[t]{2}{*}{$\begin{array}{l}\text { Control } \\
\text { number }\end{array}$} & \multicolumn{2}{|c|}{$\begin{array}{l}\text { Heterogeneity } \\
\text { test }\end{array}$} & \multirow[t]{2}{*}{$\begin{array}{l}\text { Model } \\
\text { used }\end{array}$} & \multirow[t]{2}{*}{ OR(95\%Cl) } & \multirow[t]{2}{*}{ Z } & \multirow[t]{2}{*}{$P *$} \\
\hline & & & & $P$ & $R$ & & & & \\
\hline Gender: women & 15 & 305 & 7915 & $P<0.10$ & $76 \%$ & $\begin{array}{l}\text { Random } \\
\text { effect } \\
\text { model }\end{array}$ & $\begin{array}{l}3.89[2.07, \\
7.31]\end{array}$ & 4.22 & $P<0.05$ \\
\hline $\begin{array}{l}\text { Age }(\geq 60 \text { years } \\
\text { old })\end{array}$ & 10 & 188 & 5860 & $P=0.52$ & $0 \%$ & $\begin{array}{l}\text { Random } \\
\text { effect } \\
\text { model }\end{array}$ & $\begin{array}{l}1.71[1.23 \\
2.39]\end{array}$ & 3.17 & $P=0.02$ \\
\hline Diabetes & 8 & 228 & 5789 & $P=0.61$ & $0 \%$ & $\begin{array}{l}\text { Random } \\
\text { effect } \\
\text { model }\end{array}$ & $\begin{array}{l}3.15[2.10 \\
4.72]\end{array}$ & 5.57 & $P<0.05$ \\
\hline $\begin{array}{l}\text { Blood routine } \\
\text { (white blood } \\
\text { cells } \geq 10 \times 10 \\
109 / L \text { ) }\end{array}$ & 3 & 114 & 2624 & $P=0.72$ & $0 \%$ & $\begin{array}{l}\text { Random } \\
\text { effect } \\
\text { model }\end{array}$ & $\begin{array}{l}2.86[1.66, \\
4.92]\end{array}$ & 3.78 & $P<0.05$ \\
\hline $\begin{array}{l}\text { Urine routine } \\
\text { (white blood } \\
\text { cell) }\end{array}$ & 8 & 179 & 4723 & $P=0.08$ & $45 \%$ & $\begin{array}{l}\text { Random } \\
\text { effect } \\
\text { model }\end{array}$ & $\begin{array}{l}2.43[1.35, \\
4.37]\end{array}$ & 2.96 & $P=0.003$ \\
\hline $\begin{array}{l}\text { Urine culture } \\
\text { (positive) }\end{array}$ & 8 & 168 & 4152 & $P=0.43$ & $0 \%$ & $\begin{array}{l}\text { Random } \\
\text { effect } \\
\text { model }\end{array}$ & $\begin{array}{l}1.60[1.12 \\
2.29]\end{array}$ & 2.58 & $P=0.01$ \\
\hline $\begin{array}{l}\text { Stone size } \\
(\geq 2 \mathrm{~cm})\end{array}$ & 12 & 278 & 7196 & $P=0.98$ & $0 \%$ & $\begin{array}{l}\text { Random } \\
\text { effect } \\
\text { model }\end{array}$ & $\begin{array}{l}1.94[1.49 \\
2.54]\end{array}$ & 4.85 & $P<0.05$ \\
\hline $\begin{array}{l}\text { Antler shaped } \\
\text { stone }\end{array}$ & 5 & 65 & 2511 & $P=0.68$ & $0 \%$ & $\begin{array}{l}\text { Random } \\
\text { effect } \\
\text { model }\end{array}$ & $\begin{array}{l}3.07[1.78, \\
5.31]\end{array}$ & 4.02 & $P<0.05$ \\
\hline $\begin{array}{l}\text { Hydronephrosis } \\
\text { (medium to } \\
\text { severe) }\end{array}$ & 5 & 102 & 1827 & $P=0.64$ & $0 \%$ & $\begin{array}{l}\text { Random } \\
\text { effect } \\
\text { model }\end{array}$ & $\begin{array}{l}1.57[1.02 \\
2.43]\end{array}$ & 2.03 & $P=0.04$ \\
\hline Hypertension & 5 & 107 & 2999 & $P=0.86$ & $0 \%$ & $\begin{array}{l}\text { Random } \\
\text { effect } \\
\text { model }\end{array}$ & $\begin{array}{l}1.22[0.78, \\
1.92]\end{array}$ & 0.88 & $P=0.38$ \\
\hline $\begin{array}{l}\text { History of } \\
\text { stone surgery }\end{array}$ & 7 & 181 & 3441 & $P=0.04$ & $55 \%$ & $\begin{array}{l}\text { Random } \\
\text { effect } \\
\text { model }\end{array}$ & $\begin{array}{l}1.39[0.83 \\
2.32]\end{array}$ & 1.26 & $P=0.21$ \\
\hline $\begin{array}{l}\text { Whether to use } \\
\text { antibiotics } \\
\text { before surgery }\end{array}$ & 2 & 97 & 1311 & $P=0.01$ & $83 \%$ & $\begin{array}{l}\text { Random } \\
\text { effect } \\
\text { model }\end{array}$ & $\begin{array}{l}0.77[0.24, \\
2.53]\end{array}$ & 0.43 & $P=0.67$ \\
\hline
\end{tabular}

b. PuRass Scoring System 


\begin{tabular}{|c|c|c|c|c|c|}
\hline & Variable & Indices & Score & Grade & \\
\hline \multirow[t]{4}{*}{ Basic characteristics } & \multirow[t]{2}{*}{ Sex } & Male & 3 & & \multirow[t]{18}{*}{ Total } \\
\hline & & Female & 0 & & \\
\hline & \multirow[t]{2}{*}{ Age } & $\geq 60$ years & 2 & & \\
\hline & & $\$ 60$ years & 0 & & \\
\hline \multirow[t]{2}{*}{ Past history } & \multirow[t]{2}{*}{ Diabetes Mellitus(DM) } & Positive & 3 & & \\
\hline & & Negative & 0 & & \\
\hline \multirow[t]{6}{*}{ Laboratory analysis } & \multirow[t]{2}{*}{ Blood routine (White blood cells) } & $\geq 10 \times 10^{9} / \mathrm{L}$ & 2 & & \\
\hline & & $<10 \times 10^{9} / \mathrm{L}$ & 0 & & \\
\hline & \multirow[t]{2}{*}{ 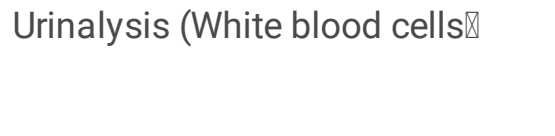 } & Positive & 2 & & \\
\hline & & Negative & 0 & & \\
\hline & \multirow[t]{2}{*}{ Urine culture } & Positive & 2 & & \\
\hline & & Negative & 0 & & \\
\hline \multirow[t]{6}{*}{ Imaging } & \multirow[t]{2}{*}{ Stone size } & $\geq 2 \mathrm{~cm}$ & 2 & & \\
\hline & & $<2 \mathrm{~cm}$ & 0 & & \\
\hline & \multirow[t]{2}{*}{ Stag horn } & Yes & 3 & & \\
\hline & & No & 0 & & \\
\hline & \multirow[t]{2}{*}{ Degree of hydronephrosis } & Moderate severe & 2 & & \\
\hline & & No/ mild & 0 & & \\
\hline
\end{tabular}

\section{Evaluation of risk assessment system}

\section{General clinical data}

A total of 293 patients (99 men and 194 women) were evaluated using the newly established scoring system. The mean age was (50.41SD11.48) years and mean stone size $(2.61 S D 1.64) \mathrm{cm}$. Among the ten case of urosepsis one patient died of complications. The reaming nine cases recovered well and discharged. The demographics are shown in Table 2.a.

Table 2 a. Patient characteristics undergoing PCNL 


\begin{tabular}{|c|c|c|c|}
\hline & & Urosepsis & Non-urological cause of sepsis \\
\hline \multirow[t]{2}{*}{ Sex } & male & 7 & 92 \\
\hline & Female & 3 & 191 \\
\hline \multirow[t]{2}{*}{ Age } & $\geq 60$ year & 4 & 53 \\
\hline & $<60$ year & 6 & 230 \\
\hline \multirow[t]{2}{*}{ Diabetes Mellitus(DM) } & With & 3 & 16 \\
\hline & Without & 7 & 267 \\
\hline \multirow[t]{2}{*}{ Blood routine (White blood cells) } & $\geq 10 \times 10^{9} / \mathrm{L}$ & 7 & 30 \\
\hline & $<10 \times 10^{9} / \mathrm{L}$ & 3 & 253 \\
\hline \multirow[t]{2}{*}{ Urinalysis (White blood cells) } & positive & 9 & 59 \\
\hline & Negative & 1 & 224 \\
\hline \multirow[t]{2}{*}{ Urine culture } & Positive & 8 & 17 \\
\hline & Negative & 2 & 266 \\
\hline \multirow[t]{2}{*}{ Stone size } & $\geq 2 \mathrm{~cm}$ & 8 & 215 \\
\hline & $<2 \mathrm{~cm}$ & 2 & 68 \\
\hline \multirow[t]{2}{*}{ Stag horn } & Yes & 1 & 1 \\
\hline & No & 9 & 282 \\
\hline \multirow[t]{2}{*}{ Degree of hydronephrosis } & Moderate severe & 6 & 114 \\
\hline & No/ mild & 4 & 179 \\
\hline
\end{tabular}

b. PuRas scale of 293 patients

\begin{tabular}{|c|c|c|c|c|c|}
\hline Group & $\mathrm{n}$ & Range & Mean & $t$ & $p$ \\
\hline Urosepsis & 10 & $4 \bigotimes 16$ & 11.70SD3.86 & 7.39 & $<0.01$ \\
\hline Non-urological cause of sepsis & 283 & $0 \otimes 15$ & $4.73 S D 2.90$ & & \\
\hline
\end{tabular}

c. PuRass Grade stratification

\begin{tabular}{|c|c|c|c|c|}
\hline & Urosepsis & Non-urological cause of sepsis & $x^{2}$ & $P$ \\
\hline Low risk & 1ه10.0ष & $249 \llbracket 88.0 \rrbracket$ & 36.18 & $<0.01$ \\
\hline Intermediate risk & $6 \rrbracket 60.0 \rrbracket$ & $33 \otimes 11.7 \rrbracket$ & & \\
\hline High risk & $3 \rrbracket 30.0 \bigotimes$ & $1 \otimes 0.3 \rrbracket$ & & \\
\hline
\end{tabular}

Effect analysis of the Risk assessment system: 
Two hundred and ninety-three patients scored between 0 16 points with an average score of (4.97SD3.19). The average score in urosepsis patient was higher than in non-urological cause sepsis and was statically significant $(P<0.01)$ Table 2.b

\section{ROC curve:}

The predictive ability of the risk assessment system was determined by ROC(Receiver Operating Characteristic ) curve with AUC $0.913 \otimes 95 \% \mathrm{Cl}[0.807-1.000]$ ). Youden's index (0.794) was used to determine the optimal cutoff values of 8.5 with a $90 \%$ sensitivity and 89.4 specificity. See Figure 1

\section{Degree of severity}

For easier and accurate evaluation, severity was graded as Low risk 0-7; medium risk 8-14, high risk 15-21. All the 293 patients were assessed for degree of severity, the difference among the groups was significant $(P<0.01)$. See Table 2.c

\section{Discussion}

Percutaneous nephrolithotomy (PCNL) was the treatment of choice for large renal calculi however, it was not free of complications. Urosepsis was a potentially catastrophic complication which could progress to multiorgan dysfunction syndrome (MODS). The risk of post-PCNL(Percutaneous Nephrolithotomy) urosepsis is $0.3-4.7 \%$ and has a mortality of $25-60 \%{ }^{[4-5]}$. Delay in diagnosis and treatment of sepsis increased mortality, prolonged length of hospital stay, and increased the costs ${ }^{[6-7]}$.

Incidence of urosepsis had increased with the increasing number of PCNL(Percutaneous nephrolithotomy) performed every year. Attempts had been made to identify factors contributing to the development of SIRS (Systemic Inflammatory Response Syndrome ). However, no single method or scoring system had been designed to predict the probability of urosepsis ${ }^{[8]}$. Risk assessment tools had been widely used in disease diagnosis and prognosis ${ }^{[9]}$. Early diagnosis and treatment of urosepsis was difficult due to lack of a predictive scoring system. The development of evaluation system based on different risk levels that could help in early recognition of urosepsis, decrease its rate of complication and improve prognosis was today's need. This study aims to evaluate the risk factors associated to urosepsis after percutaneous nephrolithotomy (PCNL) and establish a risk assessment tools that could help in early diagnosis of highrisk patients and prevent septic complications.

Tian et al ${ }^{[10]}$ included 164 post PCNL(Percutaneous Nephrolithotomy) patients to study infectious complications after percutaneous nephrolithotomy (PCNL) and established a prediction tool for postoperative complications. They proposed that patients with larger stone size and preoperative urinary tract infection were high risk patient of developing SIRS (Systemic Inflammatory Response Syndrome) and fever after the procedure. In a retrospective study ${ }^{[11]}$ over a period of 3 years Sumit Suresh Bansal and colleges concluded that stone size $>25 \mathrm{~mm}$, prolonged operative time $>120 \mathrm{~min}$, and significant bleeding requiring transfusion were significantly correlated with postoperative severe sepsis. In anorther prospective study ${ }^{[1]}$ to determine the predictors of infectious complications following PCNL(Percutaneous Nephrolithotomy), 332 patients with renal or upper ureteric calculi were divided into 2 groups depending on incidence of infectious complications. In patients with renal failure, diabetes mellitus, preoperative PCN (Percukaneous Nephrostomy) placement, staghorn calculi, severe HDN(Hemolytic Disease of the Newborn), multiple punctures, and prolonged duration of surgery. Post-PCNL(Percutaneous Nephrolithotomy)infectious complications were more commonly observed.

All these studies had some limitation mainly the small number of sample size, single center study and limited number of variables considered for evaluations. Retrospective study from single institute, which might lead to selection bias and cause-effect relationship between different biochemical parameters and co-morbid conditions were left out. Thus we 
attempted to establish a scoring system based on the meta-analysis which including 12 factors and RCT (Randomized Controlled Trial) studies which was more accurate and comprehensive to establish a clinically useful evaluation system.

We carried a meta-analysis on risk factors of urosepsis following PCNL(Percutaneous Nephrolithotomy) and based on its results formulated the PuRass(Risk Assessment Scoring System) scale. In PuRass scale evaluation, postPCNL(Percutaneous Nephrolithotomy) urosepsis group yielded higher score than in non urolological cause of urosepsis, indicating post-PCNL(Percutaneous Nephrolithotomy) urosepsis group prone to infection. The ROC(Receiver Operating Characteristic) cure with AUC (Area Under ROC Curve) 0.913 could effectively predict the probability of post-operative infection. At a cutoff value of 8.5 the specificity and sensitivity were $89.4 \%$ and $90.0 \%$ suggesting patients above the cutoff values having higher chance of acquiring post-operative infection. These were very important clinical information that could help urologist to prepare and take more precaution in these group of patients.

We performed risk assessment in 293 patients using the PuRass scale, majority of the post PCNL(Percutaneous Nephrolithotomy) patients were at moderate risk of urosepsis that was consistence to clinical practice and many published literatures.

But in majority of non-urological cause of urosepsis patients the score was low and there was a rapid decline in number of such patients with rise in the score. This helped surgeons to be more careful specially for high risk patients and avoiding associated complications.

\section{Limitation of the study}

The retrospective nature of the analysis from a region and a single institution might cause possible bias in the scoring system. Further verification from different regions or in multi center studies was needed before the widespread use of this evaluation score. Urosepsis following PCNL(Percutaneous Nephrolithotomy) depended on variety of the preoperative and perioperative factors. Earlier reports had identified number and size of tracts, bleeding, surgical time, irritants used, pelvic pressure, nephrostomy care as major factors associated with urosepsis ${ }^{[12-16]}$. But the surgeons experience and its association with incidence of urosepsis was not clear. Since preoperative factors played an important role in the incidence of urosepsis, the peri and postoperative factors were not included in the meta- analysis used to established this scoring system. Thus, this evaluation system might not be enough to precisely assess the risk of postoperative urinary sepsis.

We had developed a risk assessment system to assess the probability of urosepsis following PCNL(Percutaneous Nephrolithotomy). The clinical application and effectiveness were also validated. The risk assessment system was useful in quantification of the operative risk before surgery could help surgeons timely and accurate appraise the risk of postoperative urosepsis. It also enabled to screen high risk patients and strictly monitor these patients. Thus, this scoring system could identify the risk factors and guide to use appropriate measures to improve the prognosis of PCNL(Percutaneous Nephrolithotomy).

\section{Declarations}

\section{Funding}

पProject level: National Natural Science Foundation of China (NSFC), Project name: Study on the mechanism of CasrClaudin-14 - mediated nanobacteria induced renal calculus formation in experimental rats., Project number: 82060135;

$\square$ Project level: Key project of Gannan Medical University, Project name: Role of selective regulation of Casr-Claudin-14 pathway in experimental kidney stone formation in rats, Project number: ZD201909; 
पProject level: The project of Shihezi University, Project name: Promotion and application of urological minimally invasive technology under the mode of "co-construction of departments" Project number: CGZH201810

$\square$ Project level: The project of Shihezi University $₫$ Project name: Study on the correlation between CaSR and nanobacteria induced HK-2 cell injury Project number:ZZZC201823A

\section{Competing interests}

This manuscript titled " Urosepsis after percutaneous nephrolithotomy (PCNL) - a new prediction rule and scoring system" has not been published or presented elsewhere in part or in entirety and is not under consideration by another journal. All study participants provided informed consent, and the study design was approved by the appropriate ethics review board. We have read and understood your journal's policies, and we believe that neither the manuscript nor the study violates any of these. There are no conflicts of interest to declare.

\section{Availability of data and material}

Not applicable

\section{Authors' contributions}

We declare that this work was done by the authors named in this article and all liabilities

\section{Ethics approval and Consent to participate}

This manuscript has not been published or presented elsewhere in part or in entirety and is not under consideration by another journal. All study participants provided informed consent, and the study design was approved by the appropriate ethics review board. We have read and understood your journal's policies, and we believe that neither the manuscript nor the study violates any of these. There are no conflicts of interest to declare.

All study participants provided informed consent.

\section{Consent for publication}

All study participants consent for publication.

\section{Acknowledgements}

This work is supported by the National Natural Science Foundation of China

\section{References}

1. Neng-Bao W, Zhi-Gang X, Jin-Wen B I, et al. Diagnosis and Treatment of Urinary Sepsis[J]. medical information, 2018. \in Chinese区

2. Xiang Song-tao,Wang Shu-sheng,Gan Peng, et al. Diagnosis and therapy of uroseptic shock by percutaneous nephrolithotomy[J]. Chinese journal of urology, 2010, 031(008):520-523.(in Chinese) 
3. Luan Rong-sheng. Principles and methods of epidemiological studies[M]. 7/5000 Sichuan university press,2005. $₫ i n$ Chinese》

4. Wu Hai-yang,Zhang Zhi-gen,Li Xin-de, et al.Ten cases of acute septic shock after upper urinary tract lithotripsy were reported [J]. Chinese Journal of Urology, 2013,34(2):157-158.(in Chinese)

5. Li K, Liu C, Zhang X, et al. Risk factors for septic shock after mini-percutaneous nephrolithotripsy with holmium laser[J]. Urology,2013,81(6):1173.

6. Clifton M M, Gettman M T, Patterson D E, et al. The change in upper tract urolithiasis composition, surgical treatments and outcomes of para and quadriplegic patients over time.[J]. Urolithiasis,2014,42(5):415-419.

7. Violette P, Dion M, Tailly T, et al. Percutaneous nephrolithotomy in patients with urinary tract abnormalities.[J]. Journal of Endourology,2014,28(12):1448-1454.

8. Zhang Zheng-long $\unrhd$ Liu Xiu-heng $₫$ Luo Hong-bo. The study of risk factors and treatment for urosepsis after percutaneous nephrolithotomy[J]. International Journal of Urology and Nephrology,2017,37(2):206-209『in Chinese区.

9. TIE Peng, DUAN Wan-li. Establishment and validation of risk assessment scoring system for urinary tract infection in patients of urology department[J]. chinese journal of infection control, 2016.

10. Tian $\mathrm{Y}$, Shenghua L, Jimeng H, et al. The Evaluation of Risk Factors for Postoperative Infectious Complications after Percutaneous Nephrolithotomy[J]. BioMed Research International, 2017, 2017:1-7.

11. Bansal S S, Pawar P W, Sawant A, et al. Predictive factors for fever and sepsis following percutaneous nephrolithotomy: A review of 580 patients[J]. Urology Annals, 2017, 9(3):230.

12. Dogan HS, Guliyev F, Cetinkaya YS, Sofikerim M, Ozden E, Sahin A. Importance of microbiological evaluation in management of infectious complications following percutaneous nephrolithotomy. Int Urol Nephrol 2007;39:737742.

13. Jou YC, Lu CL, Chen FH, et al. Contributing factors for fever after tubeless percutaneous nephrolithotomy. Urology 2015;85:527-530.

14. Koras O, Bozkurt IH, Yonguc T, et al. Risk factors for postoperative infectious complications following percutaneous nephrolithotomy: A prospective clinical study. Urolithiasis 2015;43:55-60.

15. Fernandez A, Foell K, Nott L, Denstedt JD, Razvi H. Percutaneous nephrolithotripsy in patients with urinary diversions: A case-control comparison of perioperative outcomes. J Endourol 2011;25:1615-1618.

16. Gonen M, Turan H, Ozturk B, Ozkardes H. Factors affecting fever following percutaneous nephrolithotomy: A prospective clinical study. J Endourol 2008;22:2135-2138. Draga RO, Kok ET, Sorel MR, Bosch RJ, Lock

\section{Figures}




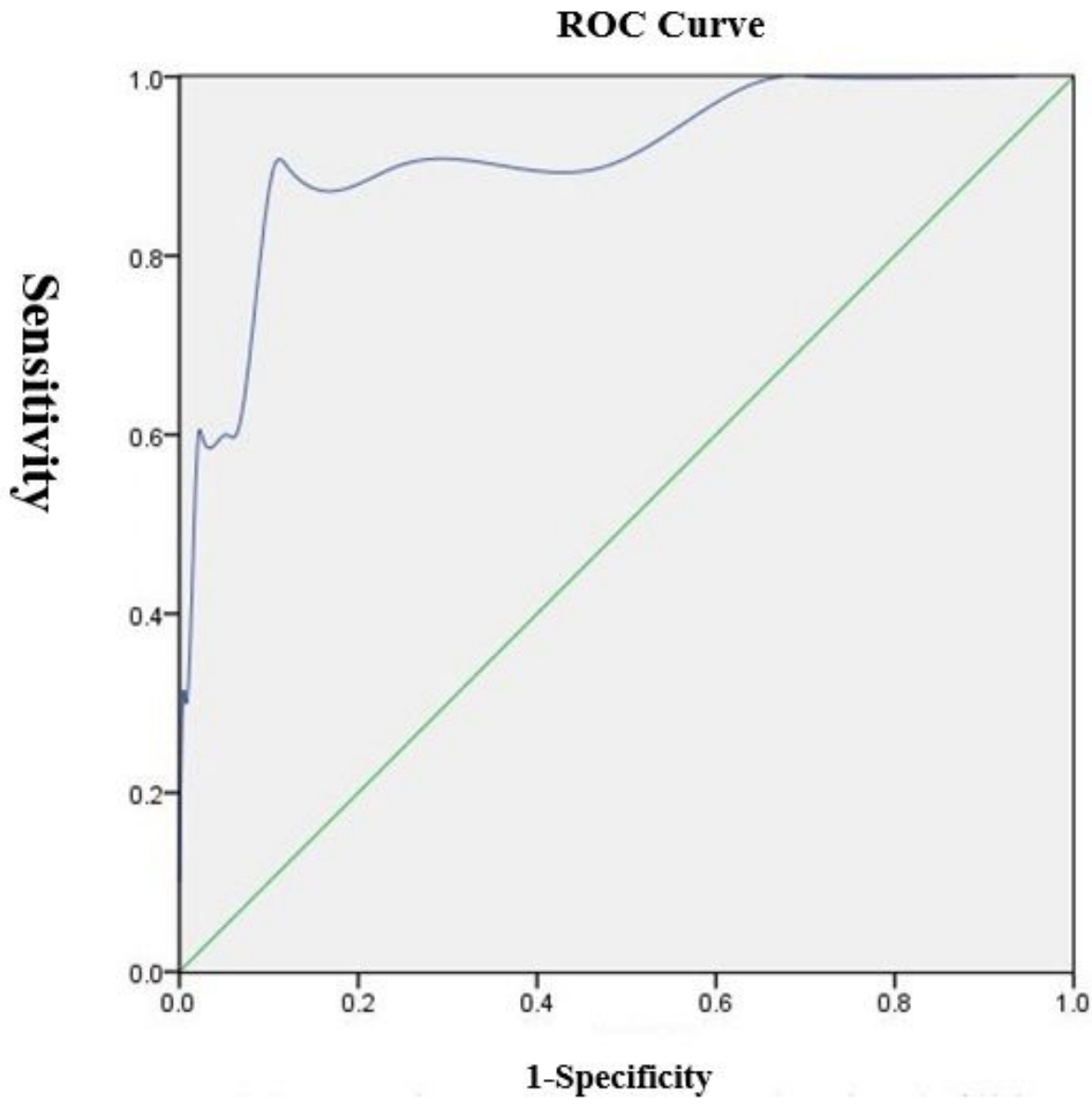

Curve Source

Risk Assessment system

Reference Line

Figure 1

ROC curve of risk assessment system for urinary sepsis after PCNL 